\title{
Manganese Diphosphine and Phosphinoamine Complexes Are Effective Catalysts for the Production of Biofuel Alcohols via the Guerbet Reaction
}

Ashley M. King, Hazel A. Sparkes, Richard L. Wingad, and Duncan F. Wass*

Cite This: Organometallics 2020, 39, 3873-3878

Read Online

ACCESS | Lلll Metrics \& More | 国 Article Recommendations ｜（s Supporting Information

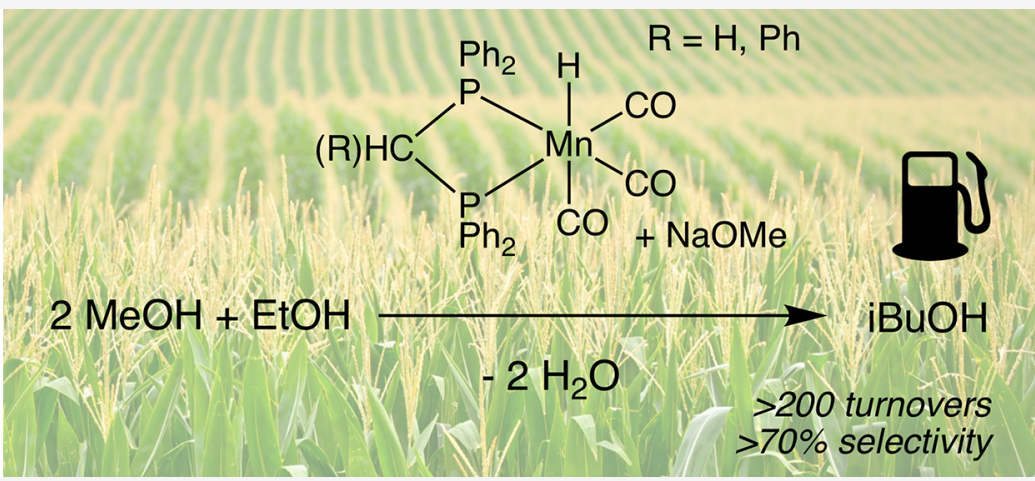

ABSTRACT: We report a variety of manganese-based catalysts containing both chelating diphosphine (bis(diphenylphosphino)methane (dppm: 1, 2, and 7) or 1,2-bis(diphenylphosphino)ethane (dppe: 3)), and mixed-donor phosphinoamine (2(diphenylphosphino)ethylamine (dppea: 4-6)) ligands for the upgrading of ethanol and methanol to the advanced biofuel isobutanol. These catalysts show moderate selectivity up to $74 \%$ along with turnover numbers greater than 100 over 90 h, with catalyst 2 supported by dppm demonstrating superior performance. The positive effect of substituting the ligand backbone was also displayed with a catalyst supported by C-phenyl-substituted dppm (8) having markedly improved performance compared to the parent dppm catalysts. Catalysts supported by the phosphinoamine ligand dppea are also active for the upgrading of ethanol to $n$ butanol. These results show that so-called PNP-pincer ligands are not a prerequisite for the use of manganese catalysts in Guerbet chemistry and that simple chelates can be used effectively.

\section{INTRODUCTION}

The search for alternative energy sources which are sustainable and meet concerns about energy security is a crucial scientific and technological goal. ${ }^{1}$ Biofuels offer an attractive alternative to liquid fossil fuels for transportation and can be economically viable and environmentally sound if the appropriate crops and agriculture methods are used. ${ }^{2,3}$ Bioethanol is widely used as a sustainable alternative fuel to conventional gasoline, often as a gasoline/bioethanol blend, but there are technological issues with this fuel: Ethanol has only $70 \%$ of the energy density of gasoline, readily absorbs water, can cause problems with separation and transportation in existing fuel infrastructure, and can be corrosive to current engine technology. ${ }^{4,5}$ By contrast, butanol isomers have emerged as an attractive option, having fuel properties similar to those of conventional gasoline. ${ }^{6,7}$ Current methods for the synthesis of butanol include the $A B E$ fermentation process, but this suffers from selectivity issues, separation problems, and low yields, making the bulk production of clean butanol a challenge. ${ }^{8-10}$ Butanol can also be accessed via hydroformylation/hydrogenation of propylene, but this relies on a nonrenewable feedstock. ${ }^{11}$

We and others have been exploring Guerbet chemistry (Scheme 1) to upgrade (bio)ethanol to $n$-butanol. ${ }^{13-20}$ This 100 year old reaction has enjoyed a renaissance in recent years as so-called borrowed hydrogen chemistry, in which a reaction sequence involving alcohol dehydrogenation to aldehyde, aldol coupling, and finally rehydrogenation to the longer chain alcohol has been established. ${ }^{21}$ Ethanol is a particularly challenging substrate for this reaction because of the high reactivity of the acetaldehyde leading to poor selectivity and multiple higher alcohol side-products; however, there are now a number of homogeneous catalysts, typically based on

Received: September 3, 2020

Published: October 26, 2020 
Scheme 1. Guerbet Reaction, As Proposed by Veibel and Nielsen $^{12}$

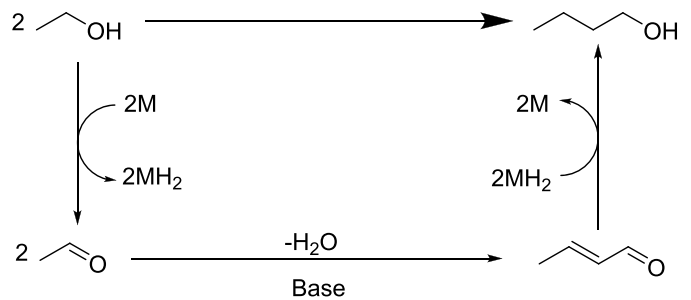

ruthenium complexes, that show good selectivity in this reaction. ${ }^{14,16,20}$ We have also extended this chemistry to the reaction of two methanol and one ethanol molecules to produce isobutanol, an even more advantaged fuel molecule, in a related sequence: Methanol and ethanol first form npropanol which then reacts with a further methanol to yield isobutanol. $^{22,23}$ Ruthenium complexes supported by bis(diphenylphosphino)methane ligands (A, Figure 1) give exceptionally high selectivity at excellent conversion in this chemistry.
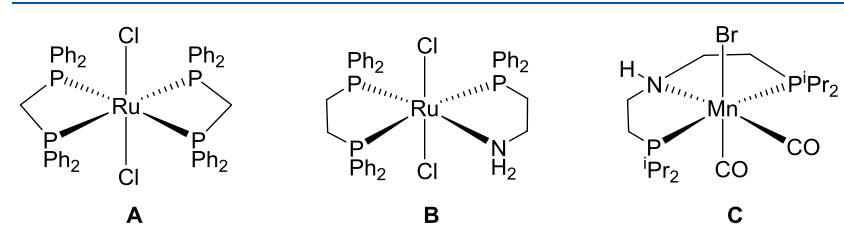

Figure 1. Variety of ruthenium and manganese-based catalysts previously used for the formation of isobutanol from methanol and ethanol.

Manganese complexes, typically based on tridentate "pincer" type ligands (C), have emerged as promising alternatives to ruthenium catalysts in many hydrogen transfer reactions not in the least because of the advantages of using an earth-abundant metal, with pioneering work by Beller. ${ }^{24-27}$ It was inevitable that such complexes would be investigated for Guerbet chemistry, and in contemporaneous work, the groups of Jones and Liu reported that such complexes are indeed active in upgrading ethanol to $n$-butanol. ${ }^{28,29}$ Liu reports extremely high turnover numbers $(>100000)$ for these catalysts by running at very low $\left(1 \times 10^{-4} \mathrm{~mol} \%\right)$ catalyst loadings for extended reaction times $(168 \mathrm{~h})$ and being satisfied with low yields (typically $<10 \%)$. Using higher catalyst loadings and shorter run times $(0.5 \mathrm{~mol} \%$ catalyst, $24 \mathrm{~h})$, Jones achieved $n$ butanol yields around $20-30 \%$. This performance is promising, and given further development, performance approaching ruthenium catalysts could be envisaged ( $\mathrm{Ru}$ : 9.6\% butanol yield using $0.1 \mathrm{~mol} \%$ catalyst $\mathrm{A}$ in $4 \mathrm{~h}$ ). More recently Liu has applied the same catalyst to isobutanol formation reporting yields of $40 \%$ with $96 \%$ selectivity over 2 days, by using high base loadings (350 mol \%). ${ }^{30}$

Manganese-catalyzed Guerbet reactions to date have exclusively been with pincer-type complexes; we were intrigued to investigate if this motif is essential for activity. Will the simple bidentate $\mathrm{P}-\mathrm{P}$ and $\mathrm{P}-\mathrm{N}$ donor ligands we have used previously also support catalytically active complexes? In this paper, we synthesize a variety of manganese bis-chelate complexes and show that these are indeed capable of catalyzing the formation of isobutanol from methanol and ethanol.

\section{SYNTHESIS OF MANGANESE COMPLEXES}

A variety of mono- and bis- chelate manganese complexes were synthesized. Complexes $\mathbf{1},{ }^{31} \mathbf{2}^{32} \mathbf{3},{ }^{31} \mathbf{5},{ }^{33} \mathbf{6}^{33}$ and $7^{34}$ (Figure 2) were synthesized according to literature procedures. 1 was
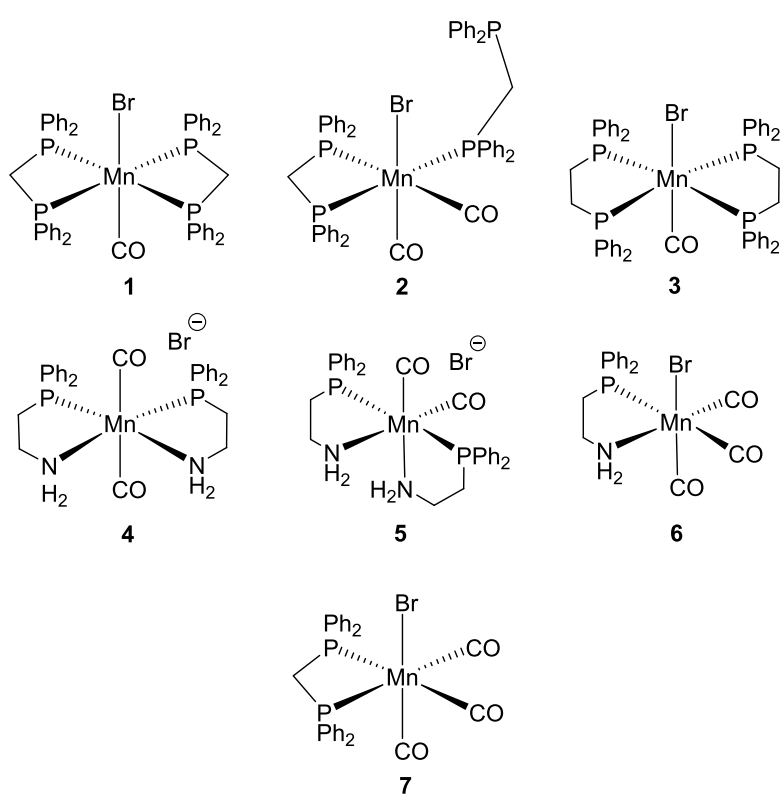

Figure 2. Manganese complexes used in this study.

obtained in $37 \%$ yield by irradiating a $2: 1$ benzene solution of the ligand and manganese precursor $\left[\mathrm{MnBr}(\mathrm{CO})_{5}\right]$ with long wave UV light. Complexes 2, 5, 6, and 7 were prepared by refluxing either a $2: 1$ or $1: 1$ solution of the ligand and manganese precursor in toluene for several hours (yields 22$54 \%)$. Complex 4 is novel and was obtained in $17 \%$ yield via the same procedure used for the production of complex 1 (Scheme 2), giving a singlet ${ }^{31} \mathrm{P}$ NMR resonance at $89 \mathrm{ppm}$ and a single stretch in the $\mathrm{CO}$ region of the IR spectrum at $1869 \mathrm{~cm}^{-1}$; these data are indicative of a trans-dicarbonyl complex. ${ }^{35}$ The diversity of structures obtained, depending on both the ligand and the preparation method, is surprising. For example, complex 1 with bis(diphenylphosphino)methane (dppm) ligands is isolated as a neutral bis chelate complex with trans $\mathrm{CO}$ and $\mathrm{Br}$ ligands, yet complex 4 with 2(diphenylphosphino)ethylamine (dppea) ligands using an identical preparation method forms the trans-dicarbonyl manganese cation with a bromide counterion. Within the dppea family of complexes, both trans- (4) and cis-isomers (5) may be isolated depending on whether a thermal or irradiation preparation method is used (Scheme 2).

Single crystals of complexes 3 (Figure $3 \mathrm{~A}$ ) and 4 (Figure 3B) were obtained from a concentrated chloroform solution (3) or from layering ethanol onto a benzene solution (4). Xray diffraction studies reveal the expected octahedral geometry in both cases, with the monodentate auxiliary ligands in the trans orientations; selected bond lengths and angles are given in the Supporting Information.

\section{CATALYST TESTING}

Using reaction conditions based on previous work with ruthenium catalysts but with longer run times $(90 \mathrm{~h}))^{22}$ catalysts 1 and 2 both produced isobutanol (14 and 11\% respectively, Table 1, runs 2 and 4). For 2, catalyst loadings 
Scheme 2. Formation of cis- and trans-Isomers of $\left[\mathrm{Mn}(\mathrm{CO})_{2}(\mathrm{dppea})_{2}\right] \mathrm{Br}$

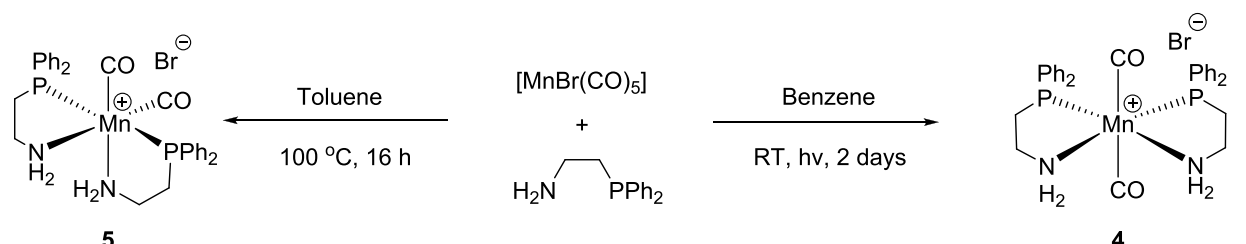

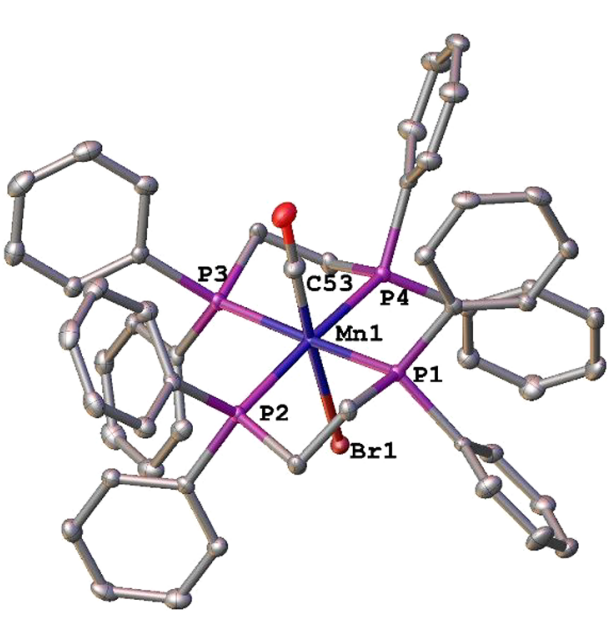

A

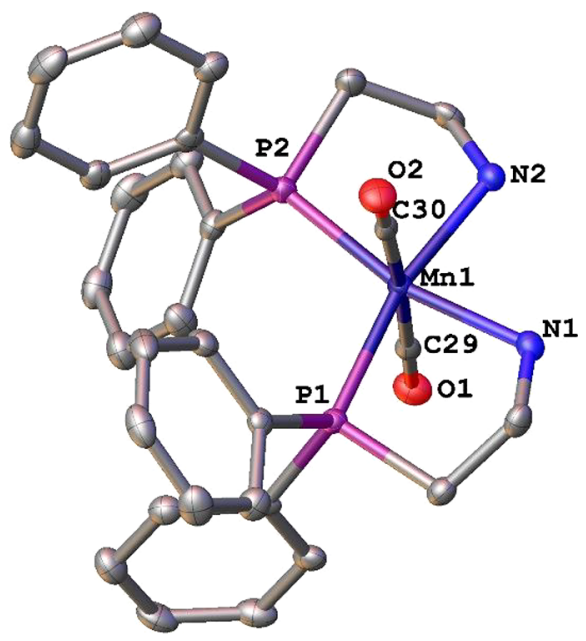

B

Figure 3. X-ray crystal structure of bis chelate complexes 3 (A) and 4 (B). Ellipsoids are depicted at the 50\% probability level. Hydrogen atoms and solvent molecules, as well as, in the case of 4 , the bromide counterion, have been omitted for clarity.

Table 1. Catalyst Screen for Isobutanol Yields

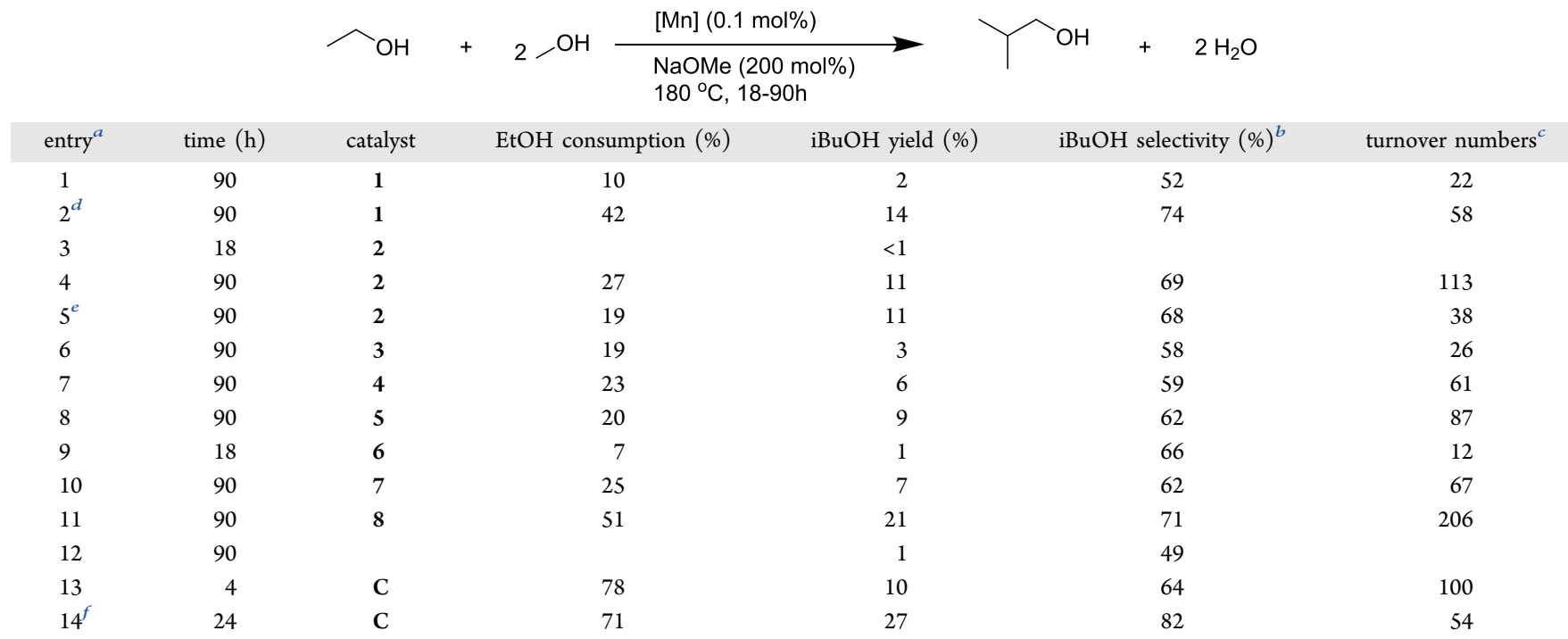

${ }^{a}$ Conditions: $1 \mathrm{~mL}(17.13 \mathrm{mmol})$ of ethanol, $10 \mathrm{~mL}$ of methanol, $180^{\circ} \mathrm{C} .{ }^{b}$ Total selectivity to isobutanol in the liquid fraction was determined by gas chromatography; see the Supporting Information for yield/selectivity of other liquid products. ${ }^{c}$ Turnover number (TON) is based on mmol of substrate converted to product per mmol of Mn. ${ }^{d}$ Using $0.3 \mathrm{~mol} \%$ catalyst. ${ }^{e}$ Using $0.25 \mathrm{~mol} \%$ catalyst, ${ }^{f}$ Using 0.5 mol \% catalyst.

could be decreased to $0.1 \%$ with no visible effect upon conversion or yield (Table 1, compare entries 4 and 5), giving turnover numbers exceeding 100. The structure-activity relationships for these manganese complexes mimic those for analogous ruthenium complexes within this limited set, so the dppm-supported complex (2) is the superior catalyst among those screened. ${ }^{14,16}$ However, while complex 2 is still active at low loadings $(0.1 \mathrm{~mol} \%)$, complex 1 requires higher loadings
( $0.3 \mathrm{~mol} \%$, entry 2$)$ before an appreciable isobutanol yield is observed. Complex 2 produces only trace amounts of isobutanol at shorter run times (18 h, entry 3$)$. At $0.1 \mathrm{~mol}$ $\%$ catalyst loading, 1,2-bis(diphenylphosphino)ethane (dppe)supported complex $\mathbf{3}$ performed similarly to $\mathbf{1}$ and is essentially inactive (run 6). The dppea-supported complexes are active at $0.1 \mathrm{~mol} \%$ catalyst loading but are still inferior to complex 2 (runs 7-9). 
It is noteworthy that while both 4 and $\mathbf{5}$ are active the cisisomer (5) marginally outperforms trans-isomer 4 (compare runs 7 and 8). A plausible explanation is that isomerization occurs slowly over the catalyst run time scale and that each isomer results in a distinct catalytic species or that there is a longer induction time for the trans-isomer to form a catalytically active species. To compare these results to a literature catalyst, the pincer complex $\mathbf{C}$ was tested under a similar protocol. $\mathbf{C}$ was more active than other catalysts after shorter run times; for example, giving $10 \%$ isobutanol after $4 \mathrm{~h}$ (entry 13) even if overall turnover numbers for $\mathbf{C}$ are similar to other catalysts if these are allowed longer run times. The high (78\%) ethanol conversion over this $4 \mathrm{~h}$ run time for C indicates a low overall selectivity for Guerbet products, with significantly more of the mass balance being solid products. In every case when catalytic activity is observed, these solids are also isolated in the postreaction mixtures, and ${ }^{1} \mathrm{H}$ and ${ }^{13} \mathrm{C}$ NMR analyses show this to be predominantly sodium formate (peak in the ${ }^{1} \mathrm{H}$ NMR spectrum at $8.45 \mathrm{ppm}$ ), which accounts for most of the remainder of the mass balance in each case between ethanol consumption and butanol yield. This formate is presumably produced via a Cannizzaro-type reaction with methanol. A small amount of sodium acetate is also seen by conversion of ethanol with the same mechanism. Interestingly, NMR spectra show an absence of any carbonate salt, in contrast to isobutanol reactions using analogous ruthenium catalysts. $^{22}$

Catalysts $\mathbf{2}$ and $\mathbf{5}$ were subsequently tested for the homocoupling of ethanol to form $n$-butanol (Scheme 3).

Scheme 3. Formation of $n$-Butanol via the Coupling of Two Ethanol Molecules

$$
2 \widehat{\mathrm{OH}} \frac{[\mathrm{Mn}]}{\begin{array}{l}
\mathrm{NaOEt}(10 \mathrm{~mol} \%) \\
150^{\circ} \mathrm{C}, 90 \mathrm{~h}
\end{array}} \rightarrow \mathrm{OH}_{\mathrm{OH}}+\mathrm{H}_{2} \mathrm{O}
$$

Owing to the rate of the catalyst appearing to be one of the limiting factors in the isobutanol chemistry, $90 \mathrm{~h}$ run times were used once again. Pleasingly, it appears catalyst $\mathbf{5}$ is also active for $n$-butanol formation with nearly 100 turnover numbers over $90 \mathrm{~h}$ (see Table S2 for further details). Unlike in isobutanol production where catalyst 2 shows little activity for this reaction, this is attributed to a lack of catalyst stability under these conditions; the postreaction mixture of $\mathbf{2}$ is dark brown, implying catalyst decomposition. This is in contrast to the postreaction mixture for catalyst $\mathbf{5}$ which is still a bright yellow homogeneous solution if kept under anaerobic conditions.

To gain insight into the active form of the best catalyst, the effect of adding base to catalyst 2 was investigated by ${ }^{31} \mathrm{P}$ NMR spectroscopy. Complex $\mathbf{2}$ is insoluble in methanol but dissolved quickly upon addition of an excess of sodium methoxide. Immediately after base addition, resonances consistent with free ligand and monochelate 7 were observed, along with minor resonances exhibiting the distinctive broadening observed upon ligand manganese complexation. This suggests a more dynamic system in which ligand redistribution is occurring; similar observations are made with ruthenium catalysts. Complex 7 was tested for isobutanol formation to ascertain whether this was the most active species (Table 1, Entry 9). Although a competent catalyst, it remains inferior to the bis-chelate complexes of the same ligand suggesting its formation is detrimental. It is not clear why dppm remains the most effective ligand for isobutanol production with both manganese and ruthenium. Given the importance of ligand-assisted mechanisms in hydrogen transfer catalysis, our working hypothesis is that involvement of the acidic hydrogens in the methylene backbone of dppm may be important; recent reports in related chemistry support this hypothesis. ${ }^{25,36,37}$

A recent paper by Kireev et al. supports our hypothesis of dppm acting as a noninnocent ligand on manganese. ${ }^{36}$ In this paper, monochelate 7 is reacted with KHMDS to form complex $\mathbf{7 b}$, containing two highly strained 3 -membered rings. This can then be converted to hydride complex $7 \mathrm{c}$ under 50 atm of hydrogen (Scheme 4). Intriguingly, this paper shows that substitution of the C-backbone atom with a phenyl group makes conversion to the hydride significantly more favorable. With this in mind, monochelate $\mathbf{8}$ was synthesized and tested for isobutanol formation in our study (Table 1, entry 10).

Pleasingly, complex 8 outperforms both monochelate 7 and the previously most effective catalyst, 2 , by a significant margin, with turnover numbers in excess of 200. This shows the potential positive effects that substitution of the dppm backbone can have toward catalytic activity for manganese complexes. Again, a plausible explanation is a ligand-assisted mechanism, that is, substitution of the backbone facilitating a more favorable cycle of hydrogenation/dehydrogenation.

In conclusion, we show that simple dppm or dppea ligand complexes of manganese are effective catalysts for the Guerbet reaction leading to butanol biofuel molecules; pincer-type complexes are not a prerequisite for competent performance. Substitution of the dppm backbone also leads to a significant increase in catalytic performance, giving isobutanol yields of $21 \%$.

\section{ASSOCIATED CONTENT}

\section{sI Supporting Information}

The Supporting Information is available free of charge at https://pubs.acs.org/doi/10.1021/acs.organomet.0c00588.

Full experimental procedures along with detailed catalytic results (PDF)

Scheme 4. Activation of Manganese Complexes Containing Substituted dppm Ligands and Their Reactivity with Hydrogen ${ }^{a a, 36}$
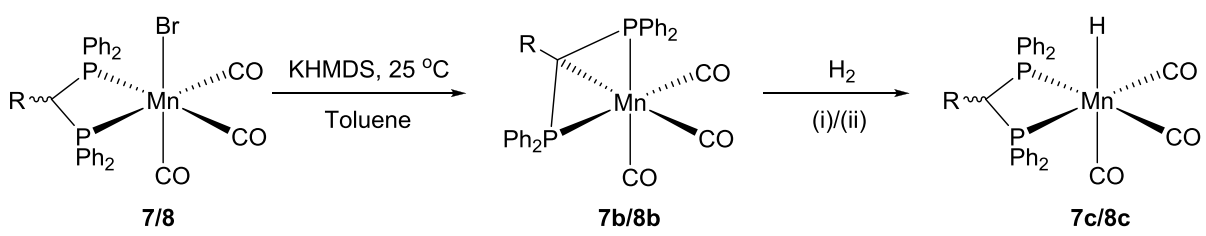

${ }^{a}$ Conditions: $7: \mathrm{R}=\mathrm{H}$, (i) 50 atm $\mathrm{H}_{2}, 50{ }^{\circ} \mathrm{C}, 16$ h. 8: $\mathrm{R}=\mathrm{Ph}$, (ii) $1 \mathrm{~atm} \mathrm{H}_{2}, 25{ }^{\circ} \mathrm{C}, 5 \mathrm{~min}$. 


\section{Accession Codes}

CCDC 2012433 and 2012434 contain the supplementary crystallographic data for this paper. These data can be obtained free of charge via www.ccdc.cam.ac.uk/data_request/cif, or by emailing data_request@ccdc.cam.ac.uk, or by contacting The Cambridge Crystallographic Data Centre, 12 Union Road, Cambridge CB2 1EZ, UK; fax: +44 1223336033.

\section{AUTHOR INFORMATION}

\section{Corresponding Author}

Duncan F. Wass - Cardiff Catalysis Institute, School of Chemistry, Cardiff University, Cardiff CF10 3AT, United Kingdom; 이이이.org/0000-0002-0356-7067; Email: WassD@Cardiff.ac.uk

\section{Authors}

Ashley M. King - Cardiff Catalysis Institute, School of Chemistry, Cardiff University, Cardiff CF10 3AT, United Kingdom

Hazel A. Sparkes - School of Chemistry, University of Bristol, Bristol BS8 1TS, United Kingdom

Richard L. Wingad - Cardiff Catalysis Institute, School of Chemistry, Cardiff University, Cardiff CF10 3AT, United Kingdom

Complete contact information is available at:

https://pubs.acs.org/10.1021/acs.organomet.0c00588

\section{Author Contributions}

The manuscript was written through contributions of all authors. All authors have given approval to the final version of the manuscript.

\section{Notes}

The authors declare no competing financial interest.

\section{ACKNOWLEDGMENTS}

We thank BP and EPSRC for funding.

\section{REFERENCES}

(1) Höök, M.; Tang, X. Depletion of Fossil Fuels and Anthropogenic Climate Change-A Review. Energy Policy 2013, 52, 797-809.

(2) Liew, W. H.; Hassim, M. H.; Ng, D. K. S. Review of Evolution, Technology and Sustainability Assessments of Biofuel Production. J. Cleaner Prod. 2014, 71, 11-29.

(3) Ragauskas, A. J.; Williams, C. K.; Davison, B. H.; Britovsek, G.; Cairney, J.; Eckert, C. A.; Frederick, W. J.; Hallett, J. P.; Leak, D. J.; Liotta, C. L.; Mielenz, J. R.; Murphy, R.; Templer, R.; Tschaplinski, T. The Path Forward for Biofuels and Biomaterials. Science 2006, 311, 484-489.

(4) Balat, M. Production of Bioethanol from Lignocellulosic Materials via the Biochemical Pathway: A Review. Energy Convers. Manage. 2011, 52, 858-875.

(5) Agarwal, A. K. Biofuels (Alcohols and Biodiesel) Applications as Fuels for Internal Combustion Engines. Prog. Energy Combust. Sci. 2007, 33, 233-271

(6) Harvey, B. G.; Meylemans, H. A. The Role of Butanol in the Development of Sustainable Fuel Technologies. J. Chem. Technol. Biotechnol. 2011, 86, 2-9.

(7) Atsumi, S.; Cann, A. F.; Connor, M. R.; Shen, C. R.; Smith, K. M.; Brynildsen, M. P.; Chou, K. J. Y.; Hanai, T.; Liao, J. C. Metabolic Engineering of Escherichia Coli for 1-Butanol Production. Metab. Eng. 2008, 10, 305-311.

(8) Green, E. M. Fermentative Production of Butanol-the Industrial Perspective. Curr. Opin. Biotechnol. 2011, 22, 337-343.
(9) Jin, C.; Yao, M.; Liu, H.; Lee, C. F. F.; Ji, J. Progress in the Production and Application of $n$-Butanol as a Biofuel. Renewable Sustainable Energy Rev. 2011, 15, 4080-4106.

(10) Bankar, S. B.; Survase, S. A.; Ojamo, H.; Granström, T. Biobutanol: The Outlook of an Academic and Industrialist. RSC Adv. 2013, 3, 24734-24757.

(11) Paulik, F. E. Recent Developments in Hydroformylation Catalysis. Catal. Rev.: Sci. Eng. 1972, 6, 49-84.

(12) Veibel, S.; Nielsen, J. I. On the Mechanism of the Guerbet Reaction. Tetrahedron 1967, 23, 1723-1733.

(13) Koda, K.; Matsu-ura, T.; Obora, Y.; Ishii, Y. Guerbet Reaction of Ethanol to $n$-Butanol Catalyzed by Iridium Complexes. Chem. Lett. 2009, 38, 838-839.

(14) Dowson, G. R. M.; Haddow, M. F.; Lee, J.; Wingad, R. L.; Wass, D. F. Catalytic Conversion of Ethanol into an Advanced Biofuel: Unprecedented Selectivity for $n$-Butanol. Angew. Chem., Int. Ed. 2013, 52, 9005-9008.

(15) Xu, G.; Lammens, T.; Liu, Q.; Wang, X.; Dong, L.; Caiazzo, A.; Ashraf, N.; Guan, J.; Mu, X. Direct Self-Condensation of Bio-Alcohols in the Aqueous Phase. Green Chem. 2014, 16, 3971-3977.

(16) Wingad, R. L.; Gates, P. J.; Street, S. T. G.; Wass, D. F. Catalytic Conversion of Ethanol to $n$-Butanol Using Ruthenium P-N Ligand Complexes. ACS Catal. 2015, 5, 5822-5826.

(17) Chakraborty, S.; Piszel, P. E.; Hayes, C. E.; Baker, R. T.; Jones, W. D. Highly Selective Formation of $n$-Butanol from Ethanol through the Guerbet Process: A Tandem Catalytic Approach. J. Am. Chem. Soc. 2015, 137, 14264-14267.

(18) Xie, Y.; Ben-David, Y.; Shimon, L. J. W.; Milstein, D. Highly Efficient Process for Production of Biofuel from Ethanol Catalyzed by Ruthenium Pincer Complexes. J. Am. Chem. Soc. 2016, 138, 90779080.

(19) Aitchison, H.; Wingad, R. L.; Wass, D. F. Homogeneous Ethanol to Butanol Catalysis: Guerbet Renewed. ACS Catal. 2016, 6, $7125-7132$

(20) Tseng, K. N. T.; Lin, S.; Kampf, J. W.; Szymczak, N. K. Upgrading Ethanol to 1-Butanol with a Homogeneous Air-Stable Ruthenium Catalyst. Chem. Commun. 2016, 52, 2901-2904.

(21) Guerbet, M. C. R. Action de l'alcool amylique de fermentation sur son dérivé iodé. C. R. Hebd. Seances Acad. Sci. 1899, 128, 10021004 (in French).

(22) Wingad, R. L.; Bergström, E. J. E.; Everett, M.; Pellow, K. J.; Wass, D. F. Catalytic Conversion of Methanol/ethanol to Isobutanol - a Highly Selective Route to an Advanced Biofuel. Chem. Commun. 2016, 52, 5202-5204.

(23) Pellow, K. J.; Wingad, R. L.; Wass, D. F. Towards the Upgrading of Fermentation Broths to Advanced Biofuels: A Water Tolerant Catalyst for the Conversion of Ethanol to Isobutanol. Catal. Sci. Technol. 2017, 7, 5128-5134.

(24) Elangovan, S.; Garbe, M.; Jiao, H.; Spannenberg, A.; Junge, K.; Beller, M. Hydrogenation of Esters to Alcohols Catalyzed by Defined Manganese Pincer Complexes. Angew. Chem., Int. Ed. 2016, 55, 15364-15368.

(25) Peña-López, M.; Piehl, P.; Elangovan, S.; Neumann, H.; Beller, M. Manganese-Catalyzed Hydrogen-Autotransfer C-C Bond Formation: $\alpha$-Alkylation of Ketones with Primary Alcohols. Angew. Chem., Int. Ed. 2016, 55, 14967-14971.

(26) Elangovan, S.; Topf, C.; Fischer, S.; Jiao, H.; Spannenberg, A.; Baumann, W.; Ludwig, R.; Junge, K.; Beller, M. Selective Catalytic Hydrogenations of Nitriles, Ketones, and Aldehydes by Well-Defined Manganese Pincer Complexes. J. Am. Chem. Soc. 2016, 138, 88098814.

(27) Elangovan, S.; Neumann, J.; Sortais, J. B.; Junge, K.; Darcel, C.; Beller, M. Efficient and Selective N-Alkylation of Amines with Alcohols Catalysed by Manganese Pincer Complexes. Nat. Commun. 2016, 7, 12641.

(28) Kulkarni, N. V.; Brennessel, W. W.; Jones, W. D. Catalytic Upgrading of Ethanol to $n$-Butanol via Manganese-Mediated Guerbet Reaction. ACS Catal. 2018, 8, 997-1002. 
(29) Fu, S.; Shao, Z.; Wang, Y.; Liu, Q. Manganese-Catalyzed Upgrading of Ethanol into 1-Butanol. J. Am. Chem. Soc. 2017, 139, 11941-11948.

(30) Liu, Y.; Shao, Z.; Wang, Y.; Xu, L.; Yu, Z.; Liu, Q. ManganeseCatalyzed Selective Upgrading of Ethanol with Methanol into Isobutanol. ChemSusChem 2019, 12, 3069-3072.

(31) Reimann, R. H.; Singleton, E. New Diphosphine-Substituted Carbonyl Complexes of Manganese. J. Organomet. Chem. 1972, 38, $113-119$

(32) Carriedo, G. A.; Riera, V.; Santamaria, J. Neutral and Cationic Dicarbonyl Complexes of Manganese (I) with Diphosphines. J. Organomet. Chem. 1982, 234, 175-183.

(33) van Putten, R.; Uslamin, E. A.; Garbe, M.; Liu, C.; Gonzalezde-Castro, A.; Lutz, M.; Junge, K.; Hensen, E. J. M.; Beller, M.; Lefort, L.; Pidko, E. A. Non-Pincer-Type Manganese Complexes as Efficient Catalysts for the Hydrogenation of Esters. Angew. Chem., Int. Ed. 2017, 56, 7531-7534.

(34) Carried, G. A.; Riera, V. Cationic Carbonyl Complexes of manganese(I) with Diphosphines. J. Organomet. Chem. 1981, 205, 371-379.

(35) Brown, D. A.; Glass, W. K.; Kreddan, K. M.; Cunningham, D.; McArdle, P. A.; Higgins, T. Reactions of Ditertiary Phosphines with n6-Arenetricarbonylmanganese Cations. J. Organomet. Chem. 1991, 418, 91-105.

(36) Kireev, N. V.; Filippov, O. A.; Gulyaeva, E. S.; Shubina, E. S.; Vendier, L.; Canac, Y.; Sortais, J. B.; Lugan, N.; Valyaev, D. A. Bis(diphenylphosphino)methane and Its Bridge-Substituted Analogues as Chemically Non-Innocent Ligands for H2 Activation. Chem. Commun. 2020, 56, 2139-2142.

(37) Ruiz, J.; Mosquera, M. E. G.; Riera, V.; Vivanco, M.; Bois, C. High Nuclearity Heterometallic gold(I)-Containing Derivatives from Manganese(I) and Ruthenium(II) Dppm Complexes via Diphosphinomethanide Intermediates. Organometallics 1997, 16, 3388-3394. 